\title{
Risk factors associated with ectopic pregnancy in our sociodemographic setup
}

\author{
Nikita Gandotra, Shazia Zargar*
}

Department of Obstetrics and Gynaecology, SMGS Hospital, Jammu, Jammu and Kashmir, India

Received: 25 July 2020

Revised: 26 August 2020

Accepted: 27 August 2020

\author{
*Correspondence: \\ Dr. Shazia Zargar, \\ E-mail: nikigandotra@gmail.com
}

Copyright: (C) the author(s), publisher and licensee Medip Academy. This is an open-access article distributed under the terms of the Creative Commons Attribution Non-Commercial License, which permits unrestricted non-commercial use, distribution, and reproduction in any medium, provided the original work is properly cited.

\begin{abstract}
Background: Ectopic pregnancy (EP) is assuming greater importance because of its increasing incidence and its impact on woman's fertility.

Aim: To assess the frequency and to determine an association between the studied risk factors and ectopic pregnancy. Methods: A retrospective study was conducted for the role of several risk factors in the occurrence of EP in department of obstetrics and Gynaecology, SMGS Hospital. A total of 110 cases and 110 controls were compared for socio demographic characteristics, cigarette smoking, obstetrical and gynaecological history, PID, past exposure to Chlamydia, surgical histories, the presence of assisted conception and contraceptive usage.

Results: The main risk factors for ectopic pregnancy were history of tuberculosis (TB) (odds ratio $(\mathrm{OR})=12.11)$, history of infertility $(\mathrm{p}=0.001)$, abortions $(\mathrm{p}=0.01)$ and a history of prior ectopic pregnancy $(\mathrm{OR}=8.549)$. Other risk factors found to be associated with an increased risk for ectopic pregnancy were Pelvic inflammatory disease (PID)/Chlamydia infection $(\mathrm{OR}=5.63)$, endometriosis (5.40), induced conception cycle $(\mathrm{OR}=3.063)$, intrauterine device usage $(\mathrm{OR}=3.55)$, prior caesarean section $(\mathrm{OR}=2.83)$ and appendectomy $(\mathrm{OR}=2.25)$. On the contrary, barrier methods $(\mathrm{OR}=0.28)$ and oral contraceptive use $(\mathrm{OR}=0.28)$ were protective from ectopic pregnancy.

Conclusion: Pelvic infection particularly TB was found to be a major etiological factor for EP in our setup. Furthermore, other factors found to be associated with ectopic pregnancy, such as prior ectopic pregnancy and infertility history may be the result of a previous pelvic infection that caused tubal sequele. Thus, these factors are potential targets for intervention and modification. Further, patients with previous abortions, pelvic surgeries, induced conception cycle and intrauterine contraceptive device (IUCD) users should be counselled about the possible risk when they conceive.
\end{abstract}

Keywords: Ectopic, Chlamydia, Tuberculosis

\section{INTRODUCTION}

An ectopic pregnancy (EP) or eccysis derived from a Greek word ektopos, out of place, is one in which the fertilized ovum becomes implanted in the site other than the normal uterine cavity. ${ }^{1,2}$ It is the result of a flaw in human reproductive physiology that allows the conceptus to implant outside the normal endometrial cavity which without timely diagnosis and treatment becomes a life threatening situation. ${ }^{3}$ Apart from being a form of reproductive failure in the index pregnancy of affected women, such women have $7-15 \%$ chances of recurrence and only 40-60\% chances of conceiving after surgery. ${ }^{4}$

Worldwide, the incidence of EP is increasing. A number of reasons at least partially explain the increased rate of EP. Some of these include increasing prevalence of sexually transmitted diseases (STDs), identification through earlier diagnosis, popularity of contraception that predisposes pregnancy failure be ectopic, tubal sterilization techniques that with contraceptive failure 
increases the likelihood of ectopic pregnancy, assisted reproductive technology and tubal surgery. ${ }^{1,4}$

It is believed that $25-50 \%$ of patients with EP have predisposing risk factors. ${ }^{5}$ Though, several studies assessing the risk factors of ectopic pregnancy have been published from both developed and developing countries. ${ }^{6}$ Risk factors and thus the incidence of the condition vary from country to country and within the same geographical region. ${ }^{7}$ Since women in our setup too have different cultural, religious, sociodemographic, sexual behaviour and beliefs and contraceptive practices, therefore the risk factors and thus the incidence of EP may differ.

\section{METHODS}

This study was conducted at SMGS Hospital, associated with Government Medical College, Jammu for a period of 12 months from January 2019 to January 2020, where 110 cases and 110 controls were studied. Ectopic pregnancy was confirmed in hospital by beta-human chorionic gonadotropin (HCG) levels, transvaginal sonography and laparoscopy/laparotomy and an equal proportion of nonectopic pregnancies were taken as controls i.e., women who delivered a single term live born neonate by vaginal or abdominal route via a uncomplicated pregnancy after index case of EP in the same center after matching some appropriate socioeconomic and sociodemographic characteristics.

A detailed history was collected from cases and controls with the help of proforma after taking written informed consent. The history included age, residence, education, occupation, socioeconomic status (modified BG Prasad scale), parity, prior abortions, prior ectopic pregnancies, post-abortal and puerperal febrile illness, tubal corrective surgeries, tubal sterilization, intrauterine contraceptive device (IUCD) use, oral contraceptive pills, post coital pills, documented tubal pathology, history of infertility, history of assisted reproductive techniques, history of pelvic inflammatory disease, history suggestive of endometriosis, history of sexual transmitted diseases and prior caesarean delivery.

An association between exposure of Chlamydia trachomatis and ectopic pregnancy was determined by testing IgG antibodies to Chlamydia trachomatis in cases and controls by using Enzyme-linked immunosorbent assay (ELISA) kits.

\section{RESULTS}

In our study, the risk of ectopic pregnancy increased with age and it remained statistically significant $(\mathrm{p}=0.012)$ and it occurred more in lower socioeconomic status as compared to controls. $(\mathrm{p}<0.001)$. Smoking increased the risk of ectopic pregnancy with odds ratio (OR) 2.57 (95\% confidence interval $(\mathrm{CI})=0.49,13.55)$ in our study. 20 cases $(18.2 \%)$ and 10 controls $(9.1 \%)$ had prior one abortion (spontaneous/induced) whereas 5 cases $(4.5 \%)$ and 1 control $(0.9 \%)$ had prior two abortions. This association was found statistically significant $(\mathrm{p}=0.01)$. Out of 110 cases, majority $(52.7 \%)$ had prior one delivery whereas majorities $(46.2 \%)$ of control were primigravida and the association was found statistically significant $(\mathrm{p}=0.008) .22(20 \%)$ of cases and $9(8.2 \%)$ of controls had evidence of pelvic inflammatory disease (PID) OR was found to be $2.806(95 \% \mathrm{CI}=1.23,6.41)$.

Among cases $11(10 \%)$ had history of tuberculosis (TB) and among controls $1(0.9 \%)$ one had such history. OR was $12.11(95 \% \mathrm{CI}=1.54,95.56)$. IgG anti Chlamydia antibody testing using ELISA kits were positive in 15 cases (13.6\%) and 3 control $(2.7 \%)$. OR was 5.63 (95\% CI=1.58, 20.06). 10 cases $(9.1 \%)$ had evidence of endometriosis and 2 controls $(1.8 \%)$ had evidence of endometriosis. OR was found to be $5.40(95 \% \mathrm{CI}=1.5,25.26)$.

Of 110 cases studied, 12 cases $(10.9 \%)$ had history of primary infertility and 8 cases $(7.3 \%)$ had history of secondary infertility, whereas of 110 controls studies, only 2 cases had history of primary infertility and only one control had history of secondary infertility. This association was statistically found to be significant ( $p<0.001$ ). $12.7 \%$ of cases and $4.5 \%$ of controls conceived after ovulation induction in present pregnancy with or of $3.063(95 \% \mathrm{CI}=1.06,8.82)$. 6 cases $(5.5 \%)$ had history of use of barrier contraception whereas 19 controls $(17.3 \%)$ had history of use of barrier contraception. OR was 0.28 $(\mathrm{CI}=0.11,0.72)$. Only 3 cases gave history of intake of levonorgestrel in index pregnancy whereas none of the controls gave such a history. OR were 7.195.5 cases $(4.5 \%)$ had history of oral contraceptive pill (OCP) use whereas of 110 controls studied, 16 controls (14.5\%) had similar history.

As per this study the rate of ectopic pregnancy among pill users was lower than non-users with $\mathrm{OR}=0.28(\mathrm{CI}=0.10$, 0.79). Pelvic surgeries were found to be associated with ectopic pregnancy. Of 110 cases, 20 cases (18.2\%) had previous history of Lower segment caesarean section (LSCS) and of 110 controls, 8 controls (7.3\%) had previous history of LSCS. OR was $2.83(\mathrm{CI}=1.19,6.75)$. with history of appendectomy or was $2.25(95 \% \mathrm{CI}=1.03$, $4.90)$, history of myomectomy or was $4.113(95 \%$ $\mathrm{CI}=0.45,37.42$ ) and history of ovarian surgery OR was $2.019(95 \% \mathrm{CI}=0.18,0.60)$. In this study $8(7.3 \%)$ cases and $1(0.9 \%)$ controls had previous history of EP. OR was $8.549(\mathrm{CI}=1.05)$.

Table 1: Age of patients.

\begin{tabular}{|c|c|c|}
\hline Age (years) & $\begin{array}{l}\text { Number of } \\
\text { cases }(\%)\end{array}$ & $\begin{array}{l}\text { Number of } \\
\text { controls }(\%)\end{array}$ \\
\hline $20-25$ & $12(10.9)$ & $34(30.9)$ \\
\hline $25-30$ & $36(32.7)$ & $36(32.8 \%)$ \\
\hline$>\mathbf{3 0}$ & $62(56.4)$ & $40(36)$. \\
\hline Total & $110(100)$ & $110(100)$ \\
\hline
\end{tabular}


Table 2: Distribution of subjects according to risk factors.

\begin{tabular}{|c|c|c|c|}
\hline Risk factors & $\begin{array}{l}\% \text { of } \\
\text { cases }\end{array}$ & $\begin{array}{l}\% \text { of } \\
\text { controls }\end{array}$ & Results \\
\hline Age $\geq 30$ years & 56.4 & 36.3 & $\mathrm{p}=0.012$ \\
\hline $\begin{array}{l}\text { Low } \\
\text { Socioeconomic } \\
\text { status }\end{array}$ & 57.2 & 8.1 & $\mathrm{p}<0.001$ \\
\hline Smoking & 4.5 & 1.8 & $\mathrm{OR}=2.57$ \\
\hline Parity $\geq 1$ & 65.6 & 51.8 & $\mathrm{p}=0.008$ \\
\hline H/o abortions & 22.7 & 10 & $\mathrm{p}=0.01$ \\
\hline PID & 20 & 8.2 & $\mathrm{OR}=2.806$ \\
\hline TB & 10 & 0.9 & $\mathrm{OR}=12.11$ \\
\hline Chlamydia & 13.6 & 2.7 & $\mathrm{OR}=5.63$ \\
\hline Endometriosis & 9.1 & 1.8 & $\mathrm{p}=0.038$ \\
\hline Infertility & 18.2 & 2.7 & $\mathrm{p}<0.001$ \\
\hline OI & 12.7 & 4.5 & $\mathrm{OR}=3.063$ \\
\hline $\begin{array}{l}\text { Barrier } \\
\text { Method }\end{array}$ & 5.5 & 17.3 & $\mathrm{OR}=0.28$ \\
\hline Post coital pill & 2.7 & 0 & $\mathrm{p}=0.245$ \\
\hline OCP & 4.5 & 14.5 & $\mathrm{OR}=0.28$ \\
\hline IUCD & 11.8 & 3.6 & $\mathrm{OR}=3.55$ \\
\hline LSCS & 18.2 & 7.3 & $\mathrm{OR}=3.55$ \\
\hline Appendectomy & 20 & 10 & $\mathrm{OR}=2.25$ \\
\hline Myomectomy & 3.6 & 0.9 & $\mathrm{OR}=4.113$ \\
\hline $\begin{array}{l}\text { Ovarian } \\
\text { Surgery }\end{array}$ & 5.5 & 0 & $\mathrm{OR}=4.283$ \\
\hline $\begin{array}{l}\text { Previous } \\
\text { Ectopic }\end{array}$ & 7.3 & 0.9 & $\mathrm{OR}=8.549$ \\
\hline
\end{tabular}

\section{DISCUSSION}

Many risk factors have been identified and implicated in the increasing incidence of ectopic pregnancy. ${ }^{3,8,9}$ In our study, the risk of EP increased with increasing age $(\mathrm{p}=0.012)$. Bouyer et al and Sivalingam et al in their study have also found this association. ${ }^{6,10}$ Ectopic pregnancy occurred more in lower socioeconomic status in present study, similar results were found by authors like Yuk et al and Aboyeji. ${ }^{11,12}$ Smoking appeared to be a risk factor in this study, with authors like Handler A et al and Bastianelli $\mathrm{C}$ at el reporting similar results. ${ }^{13,14}$

Our study depicted statistically significant association between history of abortions and EP. Similar association was reported by Tharaux-Beneux et al and Bouyer et al with $(p \leq 0.001)$ in both studies. ${ }^{6,15}$ The risk of EP increased with increasing parity. Authors like Aziz et al and Al Daheen have similar results in their respective studies. ${ }^{16,17}$ In our study, endometriosis was found to have an association with EP, similar to observations made by studies like Jobspira $\mathrm{N}$ et al and Hunter RHF. ${ }^{18,19}$

PID was seen to be associated with EP in our study. Mol B W J et al and Bouyer et al also observed the same. ${ }^{20,6} \mathrm{~TB}$ was found in $10 \%$ of cases compared to only $0.9 \%$ of controls with OR of 12.11. Ghosh et al and Shah et al have also reported association of ectopic pregnancies with tuberculosis. ${ }^{21,22} 13.6 \%$ of cases and $2.7 \%$ of controls were positive for Chlamydia IgG antibodies. These observations were comparable to the observations made by Mol et al and Agholor et al. ${ }^{20,23}$ Infertility and ovulation induction were found to be associated with EP. Studies by Malak et al and Ankum et al have also found infertility as a risk factor for EP. ${ }^{24,25}$ Authors like Karaer et al and Fernandez et al have mentioned associated of ectopic and ovulation induction. ${ }^{26,27}$

Certain types of contraception have been implicated as a risk for occurrence of EP. In our study, it was found that contraceptive methods like barrier and oral contraceptives lowered the risk. Anorlu et al and Karaer et al in their study found that barrier methods were protective from EP. 7,26 Bouyer et al and Mol et al in the study reported that the previous use of oral contraception was associated with a decreased risk of EP. ${ }^{6,28}$ Contraceptive methods like pop and IUCD were found to be a risk for EP with OR for pop as 7.19 and 3.55 for IUCD usage. Basu et al in a case presentation mentioned that a woman presented with an EP after use of levonelle-2 (a postcoital contraception) in absence of other predisposing risk factors. ${ }^{29}$ Jain et al found that hormonal emergency contraceptive pills failure rate is high when used in periovulatory period with increased chance of EP. ${ }^{30}$ Anorlu et al and Karaer et al reported that use of IUCD increased the risk of EP. ${ }^{7,26}$

Previous history of EP was found to a significant risk factor of ectopic pregnancy. Authors like Ankum et al and Karnus et al have also reported similar association. ${ }^{25,31}$ History of pelvic surgeries like LSCS, appendectomy, myomectomy and ovarian cystectomy were evaluated and found to be associated with EP. Authors like Karaer et al, Bastianelli et al, Coste et al, Michalas et al, Strandell et al and Brodowska et al in their study have found similar results. ${ }^{14,32-35}$

\section{CONCLUSION}

PID particularly TB and Chlamydia are major etiological factors for ectopic pregnancy in our setup. Furthermore, prior ectopic pregnancy and infertility history may be the result of a previous PID that might have caused tubal sequele. Advancing maternal age and low socioeconomic status are risk factor for EP possibly due to increased chances of exposure to STDs and PID. Due to increasing trend towards LSCS, risk of EP is increasing. Our study also depicted an important association between pelvic surgeries (especially appendectomy, ovarian surgery, myomectomy etc), endometriosis, induced conception cycle, post coital pill and IUCD users, and EP. Screening and early treatment for TB in reproductive age group should be done so that tubal damage can be prevented. Similarly screening and treatment for Chlamydia infection in reproductive age group is an important measure to prevent tubal damage. Women with past history of ectopic pregnancy should be kept under surveillance and counselled adequately. So that they are picked up early and 
managed accordingly. Thus, reducing their morbidity and mortality.

Funding: No funding sources Conflict of interest: None declared

Ethical approval: The study was approved by the Institutional Ethics Committee

\section{REFERENCES}

1. Cunningham FG, Leveno KJ, Bloom SL, Hauth JC, Rouse DJ and Spong CY. Ectopic pregnancy in William obstetrics, 23rd edition. 2010;10:238-9.

2. Kumar P, Malhotra N. In Jeffcoates principles of Gynaecology, 7th Edition revised and updated by Kumar P and Malhotra N. 2008;9:142-51.

3. Farguhar CM. Ectopic pregnancy Lancet. 2005;366(9485):583-591.

4. Cunningham FG, Mac Donald PC and Norman FG. Ectopic pregnancy. In William obstetric, 18th Edition. Appleton and Lanse; 1989;511-532.

5. Centers for disease control. Ectopic pregnancy United States, 1988 -1989. 1992;41:591.

6. Bouyer J, Coste J, Shojaei T, Pauly JC, Fernandez H, Gerbaud L and Job-Spira N. Risk factors for Ectopic pregnancy: A comprehensive analysis based on a large case control, population-based study in France. American Journal of Epidemiology. 2003;157(3);18594.

7. Anorlu RI, Oluwole A, Abudu OO and Adebajo S. Risk factors for Ectopic Pregnancy in Lagos, Nigeria. Acta Obstet Gynaecol scand. 2005;84(2):184-8.

8. Saraiya M, Berg CJ, Kendrick JS, Strauss LT, Atrash HK and Ahn YW. Cigarette smoking as a risk factor for ectopic pregnancy. Am J Obstet Gynecol. 1998;178(3):493-8.

9. Cleland K, Raymond E, Trussell J, Cheng L and Zhu H. Ectopic pregnancy and emergency contraceptive pills: a systematic review. Obstet Gynaecol. 2010;115(6):1263-6.

10. Sivalingam VN, Duncan WC, Kirk E, Shephard LA and Andrew W. Diagnosis and management of ectopic pregnancy. Journal of family planning and reproductive health care. 2011;37(4):231-40.

11. Yuk JS, Kim YJ, Hur JY and Shin JH. Association between socioeconomic status and ectopic pregnancy rate in the republic of Korea. Int. J. Gynaecol Obstet. 2013;122(2):104-7.

12. Aboyeji AP. Trends in Ectopic pregnancy in Ilorin, Nigeria. Nigeria Medical Practitioner. 2000;38:4-6.

13. Handler A, Davis F, Ferre C and Yeko T. The relationship of smoking and ectopic pregnancy. Am J Public Health. 1989;79(9):1239-42.

14. Bastianelli C, Lucantoni V, Valente A, Farris M, Lippa A and Dionisi B. Risk factors for ectopic pregnancy: a case control study. Minerva Gynaecol. 1998;50(11):469-73.

15. Tharaux-Beneux C, Bouyer J, Job-Spira N, Coste J and Spira A. Risk of ectopic pregnancy and previous induced abortion. Am J Public Health. 1998;88(3):401-5.

16. Aziz S, Alwafi B and Alswadi H. Frequency of ectopic pregnancy in a medical centre, kingdom of Saudi Arabia. Journal of Pakistan Medical Association. 2011;61(3):221-4.

17. Al Daheen G. Ectopic pregnancy, a prospective study in Al Batool. Teaching hospital in Mosul Iraq. Al Kindy Col Med. J. 2007;4(1):63-9.

18. Jobspira N, Collect P, Coste J, Bremond A and Laumon B. Risk factors for ectopic pregnancy. Result of a case control Study in the Rhone - Alpes region. Contracept Fertile Sex. 1993;21(4):307-12.

19. Hunter RHF. Tubal ectopic Pregnancy: A pathophysiological explanation involving endometriosis. Oxford Journals, Medicine, Human Reproduction. 2002;17(7):1688-91.

20. Mol BWJ, Ankum W M, Van deer Veen F, and Bossuyt PMM. Risk indicators for ectopic pregnancy: a meta-analysis Contraception 1995; 52: 337-41. Obstetric and Gynecological Survey. 1996;51:363-4. Fertility and Sterility. 1996;65:1093-9.

21. Ghosh K, Chowdhury JR. Tuberculosis and female reproductive health. Journal of postgraduate medicine. 2011;57(4):307-13.

22. Shah N, Khan NH. Ectopic pregnancy: presentation and risk factors. Journal of the college of physicians and surgeons Pakistan: JCPSP. 2005;15(9):535-8.

23. Agholor K, Omo Aghoja L and Okonofua F. Association of anti Chlamydia antibodies with ectopic pregnancy in Benin city, Nigeria; a case control study. African Health Sciences. 2013;13(2):430-40.

24. Malak M, Tawfeeq T, Holzer H and Tulandi T. Risk factors for Ectopic pregnancy after In vitro Fertilization Treatment. J Obstet Gynaecol Can. 2011;33(6):617-9.

25. Ankum WM, Mol BW, Vander Veen F and Bossuyt PM. Risk Factors for Ectopic Pregnancy: a metaanalysis. Fertir Steril. 1996;65(6):1093-9.

26. Karaer A, Avsar FA and Batioqlu S. Risk factors for Ectopic Pregnancy: A case-Control Study. Australian and New Zealand Journal of Obstetrics and Gynaecology. 2006;46(6):521-7.

27. Fernandez H, Coste J and Job-Spira N. Controlled Ovarian hyper stimulation as a risk factor for Ectopic Pregnancy. Obstet Gynaecol. 1991;78(4):656-9.

28. Mol BWJ, Ankum WM, Bossuyt PM and Van deer Veen F. Contraception and the risk of ectopic pregnancy: Meta-Analysis. Contraception. 1995;52:337-41

29. Basu A, Candelier C. Ectopic Pregnancy with postcoital Contraception- A case report. Eur J contracept Reprod Health Care. 2005;10(1):6-8.

30. Jain S H, Ghike S, Gawande MS, Joshi SA, Kawthalkar AS and Somalwar SA. LNG Emergency contraceptive pills: Risk factors for pregnancy. J South Asian Feder Obst Gynae. 2013;5(2):87-8.

31. Karnus LL, Egerup P, Skovlund C W and Lidegaard O. Long-term reproductive outcomes in women whose first pregnancy is ectopic: a national controlled 
follow-up study. Oxford journals, Medicine, Human Reproduction journal. 2012;28(1):241-6.

32. Coste J, Job-Spira N, Fernandez H, Papiemik E and Spira A. Risk factors for ectopic pregnancy: A Case control Study in France, with special Focus on infectious factors. Am. J. Epidemiol. 1991;133(9):839-9.

33. Michalas S, Minaretzis D, Tsionou C, Maos G, Kioses E and Aravantinos D. Pelvic Surgery, reproductive factors and risk of ectopic pregnancy: a casecontrolled study. Int. J Gynaecol Obstet. 1992;38(2):101-5.

34. Strandell A, Thorburn $\mathbf{J}$ and Hamberger L. Risk factors for Ectopic pregnancy in assisted
Reproduction. Fertility and Stertility. 1999;71(2):2826.

35. Brodowska A, Szydlowska I, Starczewski A, Strojny K, Puchalski A, Mieczkowska E and Wozniak W. Analysis of risk factors for ectopic pregnancy in own material in the years 1993-2002. Europe Pub Med Central. 2005;18(103):74-7.

Cite this article as: Gandotra N, Zargar S. Risk factors associated with ectopic pregnancy in our sociodemographic setup. Int J Reprod Contracept Obstet Gynecol 2020;9:4150-4. 